\title{
Response Surface Modeling and Optimization of Electrospun Nanofiber Membranes
}

\author{
M. Essalhi, M. Khayet, C. Cojocaru, M.C. García-Payo and P. Arribas \\ Department of Applied Physics I, Faculty of Physics, Avda. Complutense s/n, University Complutense of Madrid, Spain
}

\begin{abstract}
The experimental design and response surface methodology (RSM) have been used to develop predictive models for simulation and optimization of electrospun polyvinylidene fluoride non-woven membranes. The objective is to prepare electrospun fibers with small diameters and narrow diameter distribution. The factors considered for experimental design were the polymer dope solution flow rate, the applied electric voltage and the distance between the needle tip and the collector. A full factorial design was considered. The obtained electrospun fibers were characterized by scanning electron microscopy. The response for the model was the quality loss function that takes into account the quadratic effects of both the weighted arithmetic mean of the fibers diameter and the standard deviation. Minimal output response has been predicted and confirmed experimentally. The optimum operating conditions guarantying a small polyvinylidene fluoride nanofiber diameter with a narrow distribution were a voltage of $24.1 \mathrm{kV}$, an air gap of $27.7 \mathrm{~cm}$ and a polymer flow rate of $1.23 \mathrm{~mL} / \mathrm{h}$. The fabricated optimum membrane was characterized by different techniques and applied for desalination by membrane distillation. The obtained permeate fluxes in this study are higher than those reported so far for electrospun nanofibrous membranes.
\end{abstract}

Keywords: Electrospinning, membrane, response surface methodology, central composite design, optimization, polyvinylidene fluoride, membrane distillation.

\section{INTRODUCTION}

Electrospinning has been recognized as an efficient technique for the fabrication of polymer nanofibers. These have attracted increasing attentions in the last ten years because of their very large surface area to volume ratio, flexibility in surface functionalities and superior mechanical performance compared with any other known form of materials. These outstanding properties make the polymer nanofibers optimal candidates for many advanced applications in fields such as biomedical engineering and biotechnology, environmental engineering, energy storage, tissue engineering, drug delivery, affinity membranes, enzyme immobilization, etc [1-6].

Electrospinning can also organize nanofibers of various types such as porous, hollow and core/sheath into welldefined arrays or hierarchical architectures in threedimensional networks. Numerous studies have been carried out to gain deep understanding of the process for a better control of fiber formation [7-14].

Nowadays, systematic investigations of the effects of electrospinning variables on diameter and morphology of the electrospun fibers are of great interest. Obviously, there is an important need to produce fibers with small and uniform size so that the electrospinning process can be reproduced in large industrial applications $[2,5,15]$. Many parameters can

*Address correspondence to this author at the Department of Applied Physics I, Faculty of Physics, Avda. Complutense s/n, University Complutense of Madrid, Spain; Tel: +34-91-394-5185; Fax: +34-91-394-5191; E-mail:khayetm@fis.ucm.es affect the morphological structure and dimensions of electrospun fibers. These are system parameters such as polymer type and its molecular weight, polymer concentration, solvent type and polymer solution properties (viscosity, conductivity and surface tension); process parameters such as electric potential or voltage, flow rate of polymer solution, distance between the capillary and collector and ambient parameters (temperature, humidity and air velocity) [7-10, 1621]. Moreover, for preparation of nanofibrous membranes, the conventional or classical method of experimentation, which involves changing one of the independent parameters while maintaining the others fixed at given values, has been considered [16-21]. As it is well known, this conventional method of experimentation involves many tests, which are time-consuming, ignores interaction effects between the operating parameters and induces a low efficiency in optimization. These limitations can be avoided by applying the Response Surface Methodology (RSM) that involves statistical design of experiments (DoE) in which all factors are varied together over a set of experimental runs [22, 23]. In fact, the statistical method of experimental design offers several advantages over the frequently used conventional method being rapid and reliable, helps in understanding the interaction effects between factors and reduces the total number of experiments tremendously resulting in saving time and costs of experimentation. Moreover, RSM can be used to evaluate the relative significance of several affecting factors even in the presence of complex interactions [22-29].

In recent years various statistical experimental designs and RSM have been applied progressively to different processes [22-29]. However, among them few reports were dedi- 

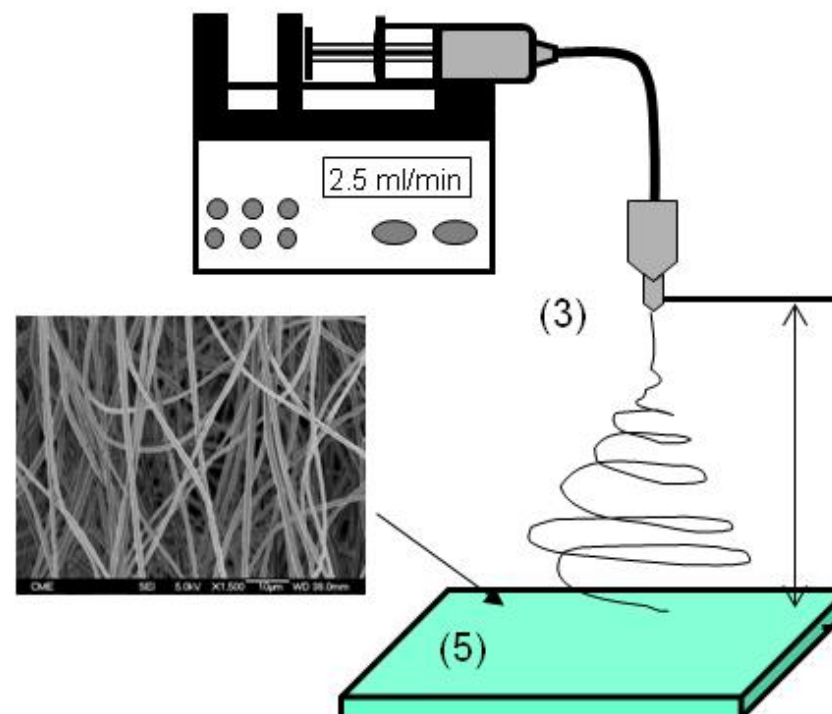

(4)

(2)

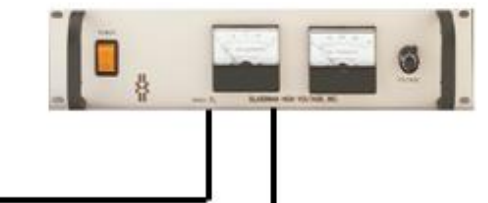

Fig. (1). Schematic diagram of electrospinning set-up. (1) Syringe with polymer solution, (2) high voltage supply, (3) spinneret, (4) distance between the needle tip and the collector, (5) collector.

cated to electrospinning [20,30]. Yördem et al. [20] studied the effects of electrospinning parameters on polyacrylonitrile (PAN) nanofiber diameter using RSM. Their investigations were carried out using only two variables (applied voltage, solution concentration) but several collector distances. The effect of the applied voltage on fiber diameter was insignificant when the solution concentration and collector distance were high. Similarly, Gu et al. [30] applied RSM for PAN nano-fibers and also reported no significant effect of the voltage on the PAN nanofibers. Both studies have been conducted considering two variables while the third parameter was maintained fixed, and therefore possible interactions between the three parameters were not studied $[20,30]$.

Polyvinylidene fluoride (PVDF) is an attractive material used in many applications due to its outstanding properties such as high mechanical strength, thermal stability, chemical resistance and good electrochemical stability compared to other commercialized polymeric materials. Electrospinning technique has also been applied to the fabrication of PVDF nanofibers and fibrous thin films for various applications [11-14].

In the present study a full factorial experimental design for fabrication of electrospun PVDF fibers has been considered. The polymer solution parameters (polymer type, molecular weight, solvents) and the environmental conditions (temperature and humidity) are maintained the same to prepare all ENMs. The main objective of this paper is to investigate the individual and mutual effects of the electrospinning variables (applied voltage, polymer solution flow rate and distance between the needle tip and the collector) on the diameter of the electrospun PVDF fibers as well as on fiber distribution. Furthermore, the optimum electrospinning conditions to ensure minimum fiber diameter with a narrow size distribution has been determined. An interesting application for ENMs is the non-isothermal distillation, which can be carried out for advanced water treatments without applying any transmembrane hydrostatic pressure and therefore selfsustained webs can be used [31-35]. Therefore, the fabricated optimum membrane was characterized by different techniques and applied for desalination by direct contact membrane distillation (DCMD) using different salt $(\mathrm{NaCl})$ aqueous concentrations. The DCMD performance is compared to other electrospun nanofibrous membranes [34, 35].

\section{MATERIALS AND METHODOLOGY}

\subsection{Materials}

The spinning solutions were prepared from the polymer PVDF $\left(M_{w}=275 \mathrm{~kg} / \mathrm{mol}\right.$ and $\left.M_{n}=107 \mathrm{~kg} / \mathrm{mol}\right)$ and the mixed solvents $N, N$-dimethyl acetamide (DMAC) and acetone purchased from Sigma-Aldrich Chemical Co. Isopropyl alcohol (IPA) was used to determine the void volume fraction and the size of the inter-fiber space, and the sodium chloride $(\mathrm{NaCl})$ used in DCMD experiments was also purchased from Sigma-Aldrich Chemical Co.

\subsection{Preparation of Electro-Spun PVDF Fibers}

The polymer solution was prepared using $25 \mathrm{wt} \%$ PVDF in the mixture $20 \mathrm{wt} \%$ acetone in DMAC. The electrospinning set-up is shown in Fig. (1) and consists of a syringe (50 $\mathrm{ml}$, Nikepal) to hold the polymer solution, a pump (KDS Scientific, model 200), two electrodes (a metallic needle of $0.60 \mathrm{~mm}$ internal diameter and a grounded copper collector covered with aluminum foil) and a DC voltage supply in the $\mathrm{kV}$ range (Iseg, TCIP300 304p). The formed fibers were then dried in an oven at $80^{\circ} \mathrm{C}$ for $5 \mathrm{~min}$ (i.e. post-treatment).

PVDF electrospun fibers have been prepared following the experimental design conditions summarized in Table $\mathbf{1}$. The electrospinning parameters are the dope solution flow rate $F(\mathrm{~mL} / \mathrm{h})$, the voltage $U(\mathrm{kV})$ and the distance $A(\mathrm{~cm})$ between the needle tip and the collector, named hereafter as collector distance. 
Table 1. Full Factorial Design for Electrospinning Experiments

\begin{tabular}{|c|c|c|c|c|c|c|}
\hline \multirow{2}{*}{ Run } & \multicolumn{2}{|c|}{ Voltage } & \multicolumn{2}{|c|}{ Collector Distance } & \multicolumn{2}{|c|}{ Polymer Flow Rate } \\
\hline & $x_{1}$ & $U(k V)$ & $x_{2}$ & $A(\mathrm{~cm})$ & $x_{3}$ & $F(m L / h)$ \\
\hline B1 & +1 & 24.5 & +1 & 28.23 & +1 & 3.28 \\
\hline B2 & -1 & 10.5 & +1 & 28.23 & +1 & 3.28 \\
\hline B3 & +1 & 24.5 & -1 & 11.77 & +1 & 3.28 \\
\hline B4 & -1 & 10.5 & -1 & 11.77 & +1 & 3.28 \\
\hline B5 & +1 & 24.5 & +1 & 28.23 & -1 & 1.22 \\
\hline B6 & -1 & 10.5 & +1 & 28.23 & -1 & 1.22 \\
\hline B7 & +1 & 24.5 & -1 & 11.77 & -1 & 1.22 \\
\hline B8 & -1 & 10.5 & -1 & 11.77 & -1 & 1.22 \\
\hline B9 & 0 & 17.5 & 0 & 20 & 0 & 2.25 \\
\hline $\mathrm{B} 10$ & 0 & 17.5 & 0 & 20 & 0 & 2.25 \\
\hline
\end{tabular}

\subsection{Characterization}

The surface of the non-woven electrospun PVDF membranes was examined by a field emission scanning electron microscope (FESEM, JEOL Model JSM-6330F). Micrographs from the SEM analysis were analyzed by UTHSCSA ImageTool 3.0 to determine the fiber diameter. For each sample more than 5 SEM images have been considered and the diameters of a total number of 100 fibers have been measured. Statistical analysis have been applied in order to determine the fiber size distribution and to estimate the arithmetic weighted mean of the fiber diameters and their dispersion (i.e. weighted standard deviation).

The electrospun nanofibrous PVDF membrane, prepared using the obtained optimum electrospinning conditions over a period of $3 \mathrm{~h} 30 \mathrm{~min}$, was characterized by different techniques to determine the liquid entry pressure (LEP) of distilled water and saline aqueous solutions of different concentrations $(12 \mathrm{~g} / \mathrm{L}, 30 \mathrm{~g} / \mathrm{L}$ and $60 \mathrm{~g} / \mathrm{L})$, the mean size of the inter-fiber space $\left(d_{i}\right)$ by the wet/dry flow method, the advancing water contact angle $\left(\theta_{a}\right)$ by a computerized optical system CAM100 (7.1 $\mu \mathrm{L}$ water drop), the void volume fraction $(\varepsilon)$ from density measurements and the thickness $(\delta)$ by the micrometer Millitron Phywe (Mahr Feinprüf, type TYP1202IC). Details of the characterization techniques used are explained elsewhere [32].

Direct contact membrane distillation (DCMD) was carried out using the fabricated optimum electrospun PVDF membrane under different salt $(\mathrm{NaCl})$ concentrations $(0 \mathrm{~g} / \mathrm{L}$, $12 \mathrm{~g} / \mathrm{L}, 30 \mathrm{~g} / \mathrm{L}$ and $60 \mathrm{~g} / \mathrm{L})$, a feed temperature of $80^{\circ} \mathrm{C}$ and permeate temperature of $20^{\circ} \mathrm{C}$ and a stirring rate of both the feed and permeate of $500 \mathrm{rpm}$. The experimental system used is detailed in [36].

\section{RESULTS AND DISCUSSIONS}

The SEM images, together with their corresponding histograms showing the sizes of the electrospun fibers, are presented in Fig. (2). Differences exist between the SEM images of the samples depending on the electrospinning conditions. The best electrospun fibers have been obtained for the experimental run 5 (B5 in Fig. 2). The corresponding elec- trospinning values facilitate stretching of polymer solution along the distance between the needle and the collector and enhance the solvent evaporation leading to the formation of electrospun fibers with small diameters. The worst spinning conditions correspond to the experimental run 4 (B4 in Fig. 2), which involves the setting of factors at the opposite levels to those in experimental run 5. Such conditions seem to hinder solvent evaporation leading to fusion of fibers. As a result, more fiber-to-fiber contacts are formed.

Based on the statistical analysis of the histograms shown in Fig. (2), the weighted arithmetic mean $\left(\lambda_{w}\right)$ of the fiber diameters and the corresponding weighted standard deviation $\left(s_{w}\right)$ have been determined as follows [37]:

$\lambda_{w}=\lambda_{0}+\frac{h}{N} \sum_{j=1}^{m} u_{j} \cdot F C_{j}$

$S_{w}=\sqrt{\left(\frac{1}{N} \cdot \sum_{j=1}^{m}\left(u_{j}^{2} \cdot F C_{j}\right)-\left(\frac{1}{N} \cdot \sum_{j=1}^{m}\left(u_{j} \cdot F C_{j}\right)\right)^{2}\right) \cdot h^{2}}$

where $m$ denotes the number of bins (disjoint categories), $h$ is the bin width, $h=\left(\lambda_{\max }-\lambda_{\min }\right) / m, F C$ is the frequency count, $N$ is the number of samples in the statistical set (in our case $N=100), \lambda_{0}$ is the dominant characteristic of the statistical set that corresponds to the highest peak, $u$ is a variable defined as $u=\left(\lambda_{\mathrm{c}}-\lambda_{0}\right) / h$ and $\lambda_{\mathrm{c}}$ is the bin characteristic (or bin center).

Finally, the quality loss function $(Y)$ that summarizes the quadratic effect of both weighted arithmetic mean and standard deviation as response for factorial modeling and optimization has been considered. This response is defined as follows [37, 38]:

$Y=\lambda_{w}^{2}+s_{w}^{2}$

In this case low $Y$ value means good electrospinning process performance (i.e. low values of $\lambda_{w}$ and $s_{w}$ ). Table 2 summarizes the obtained values of $\lambda_{w}, s_{w}$ and $Y$ determined according to the experimental design. In general, it was found that an increase of $s_{w}$ is associated to $\lambda_{w}$. The electrospun fiber 

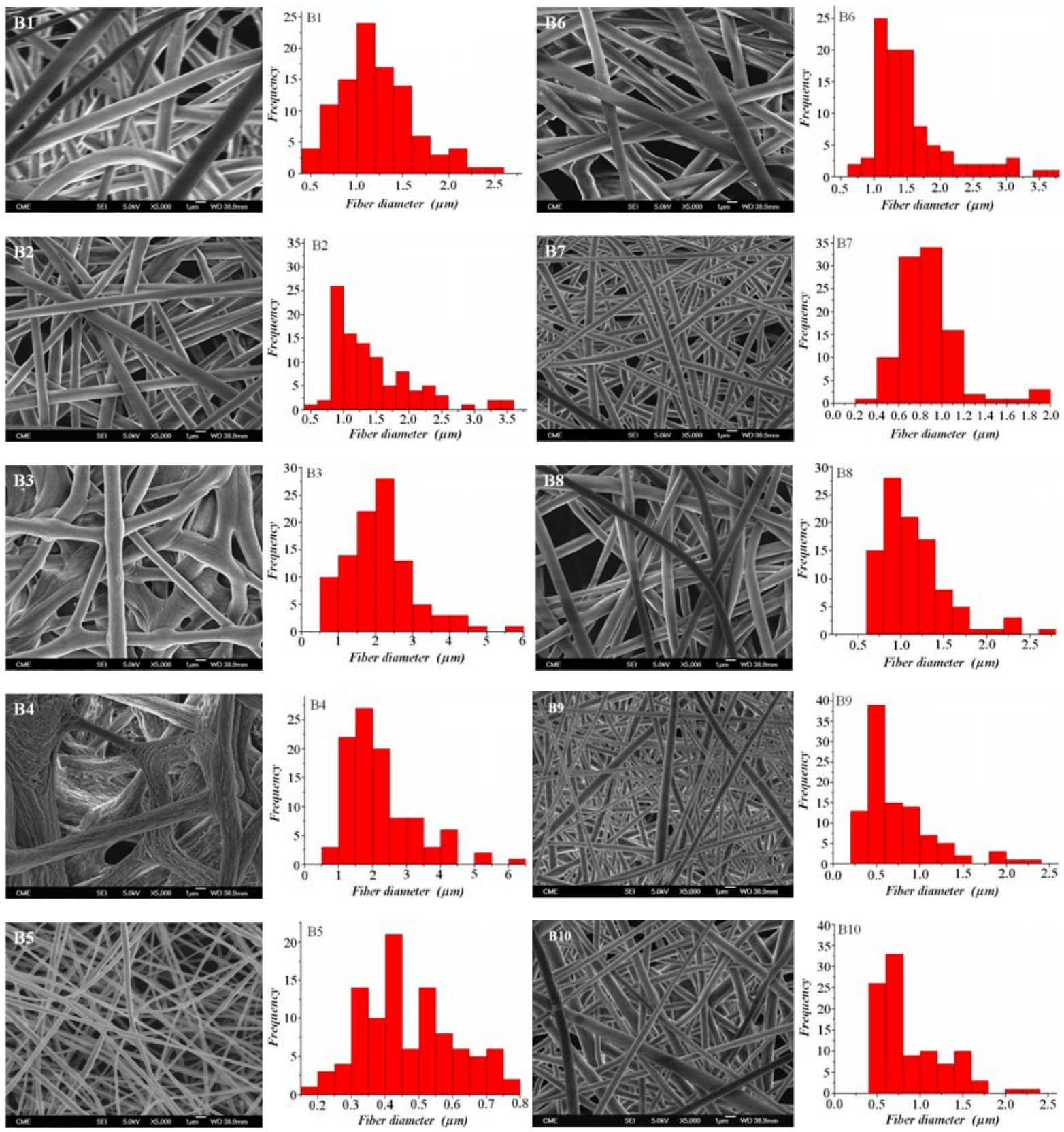

Fig. (2). SEM images of electrospun PVDF fibers $(B 1, B 2, B 3, \ldots B 10)$ prepared applying the electrospinning experimental runs summarized in Table 1.

Table 2. Responses Resulted from Statistical Analysis of Electrospun Fiber Diameter Distributions

\begin{tabular}{|c|c|c|c|}
\hline Membrane & $\begin{array}{c}\lambda_{w} \\
(\mu \mathbf{m})\end{array}$ & $\begin{array}{c}\boldsymbol{S}_{w} \\
(\mu \mathbf{m})\end{array}$ & $Y=\lambda_{w}^{2}+s_{w}^{2}\left(\mu \mathbf{m}^{2}\right)$ \\
\hline \hline B1 & 1.218 & 0.410 & 1.652 \\
\hline B2 & 1.452 & 0.633 & 2.509 \\
\hline B3 & 2.130 & 0.928 & 5.398 \\
\hline B4 & 2.235 & 1.050 & 6.098 \\
\hline B5 & 0.470 & 0.138 & 0.240 \\
\hline B6 & 1.564 & 0.599 & 2.805 \\
\hline B7 & 0.874 & 0.285 & 0.845 \\
\hline
\end{tabular}


Table 2. contd....

\begin{tabular}{|c|c|c|c|}
\hline Membrane & $\begin{array}{c}\lambda_{w} \\
(\mu \mathbf{m})\end{array}$ & $\begin{array}{c}\boldsymbol{s}_{w} \\
(\mu \mathbf{m})\end{array}$ \\
\hline \hline B8 & 1.150 & 0.394 & 1.478 \\
\hline B9 & 0.738 & 0.413 & 0.715 \\
\hline B10 & 0.828 & 0.399 & 0.844 \\
\hline
\end{tabular}

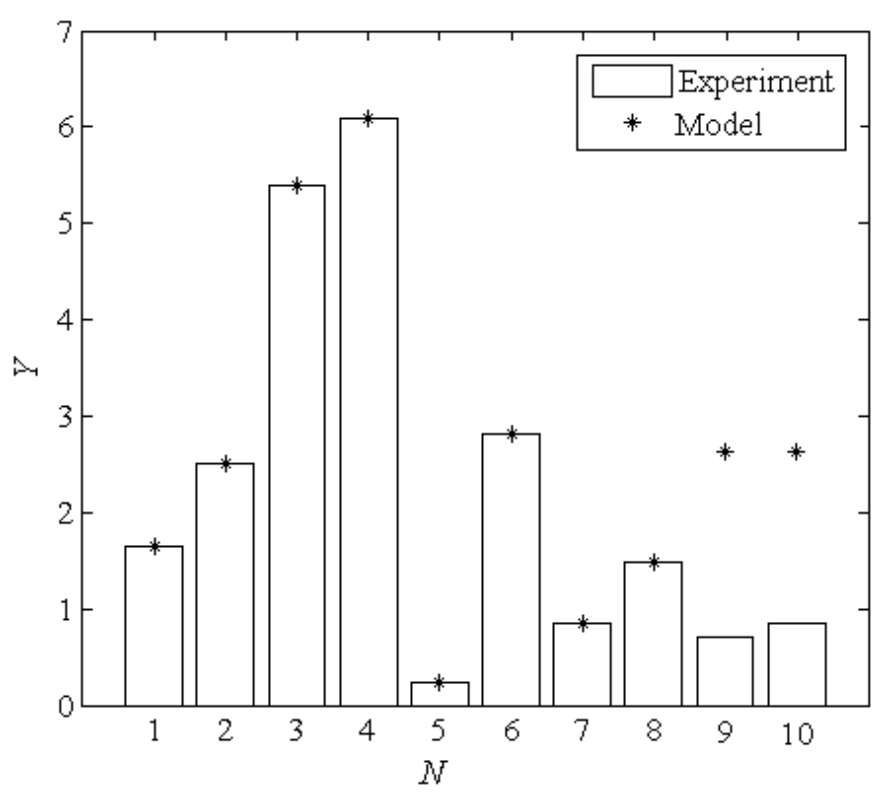

Fig. (3). Comparison between experimental and predicted data by the developed factorial model.

sample B5 exhibits the lowest values of $\lambda_{w}, s_{w}$ and $Y$. In contrast, the electro-spun fiber sample B4 has the highest values of $\lambda_{w}, s_{w}$ and $Y$.

Based on the regression techniques and the results presented in Tables $\mathbf{1}$ and $\mathbf{2}$, a factorial model with interactions has been developed. Eq. (4) shows the obtained factorial model in terms of coded variables:

$$
\begin{aligned}
& \hat{Y}=2.628-0.594 x_{1}-0.827 x_{2}+1.286 x_{3} \\
& -0.261 x_{1} x_{2}+0.205 x_{1} x_{3}-1.007 x_{2} x_{3}+0.222 x_{1} x_{2} x_{3}
\end{aligned}
$$

subjected to: $-1 \leq x_{i} \leq+1 ; \forall i=\overline{1,3}$

where $\hat{Y}$ is the predictor of the response (quality loss function, $Y$ ). The significance of each individual regression coefficient has been tested by means of Student's $t$-test [39].

The analysis of variance (ANOVA) has been used to check the statistical significance of the factorial model. $F$ value has been determined based on the ratio of the mean square of group variance due to the error [40]. The larger is the difference of $F$-value from unity, the more certain it is that the designed variables (factors) adequately explain the variation in the mean of the data. In this case, the $F$-value is higher than 1 (2.159) and the coefficient of multiple determination $R^{2}$ indicated that $81.2 \%$ of the data variation can be explained by the factorial model. Therefore, the developed interaction factorial model can be accepted for the prediction of the response in the considered range of experimentation (valid region). It must be pointed out that the obtained regression coefficients in Eq. (4) can not be considered for electrospun modelling of other polymer solutions and other environmental conditions (i.e. temperature and humidity). The same DoE and RSM can be applied and other regression coefficients may be obtained.

Fig. (3) reports a comparison of the predicted and experimentally measured response. The predicted data are almost identical to the experimental ones for the orthogonal points (i.e runs 1-8). However, for the center point (i.e. runs 9 and 10) the discrepancy between the predicted and experimental data is higher compared to the other experimental runs. This means that the regression equation does not describe very accurately the response in the center point. This behaviour can be attributed to the orthogonal property of the factorial design. However, based on the ANOVA statistical test the overall prediction may be considered satisfactory.

For graphical representation and analysis of response surface, the factorial model in terms of coded variables has been converted to an empirical model in terms of actual variables. The obtained factorial model in terms of actual variables is as follows:

$$
\begin{aligned}
& \hat{Y}=-5.445+0.11 U+0.393 A+4.436 F-0.013 U A \\
& -0.046 U F-0.184 A F+3.741 \times 10^{-3} U A F
\end{aligned}
$$



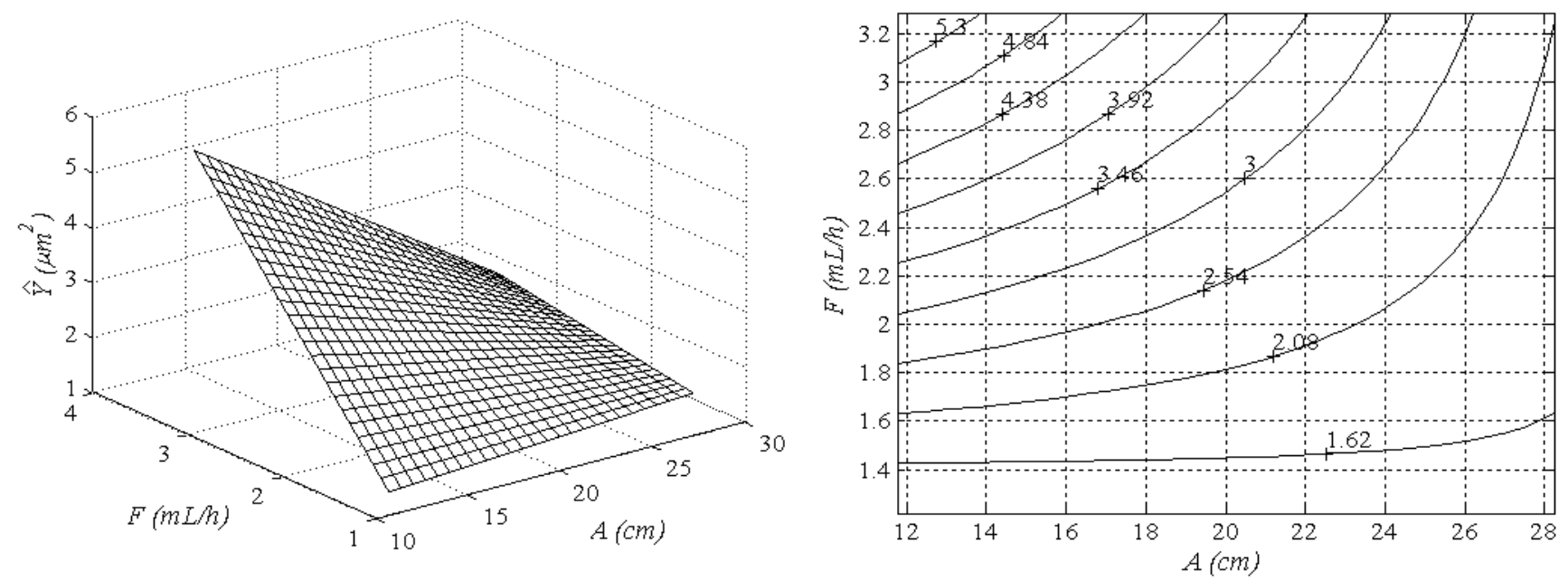

Fig. (4). Quality loss function $(Y)$ versus the variables $F(\mathrm{~mL} / \mathrm{h})$ and $A(\mathrm{~cm})$ maintaining $U$ at $17.5 \mathrm{kV}$.
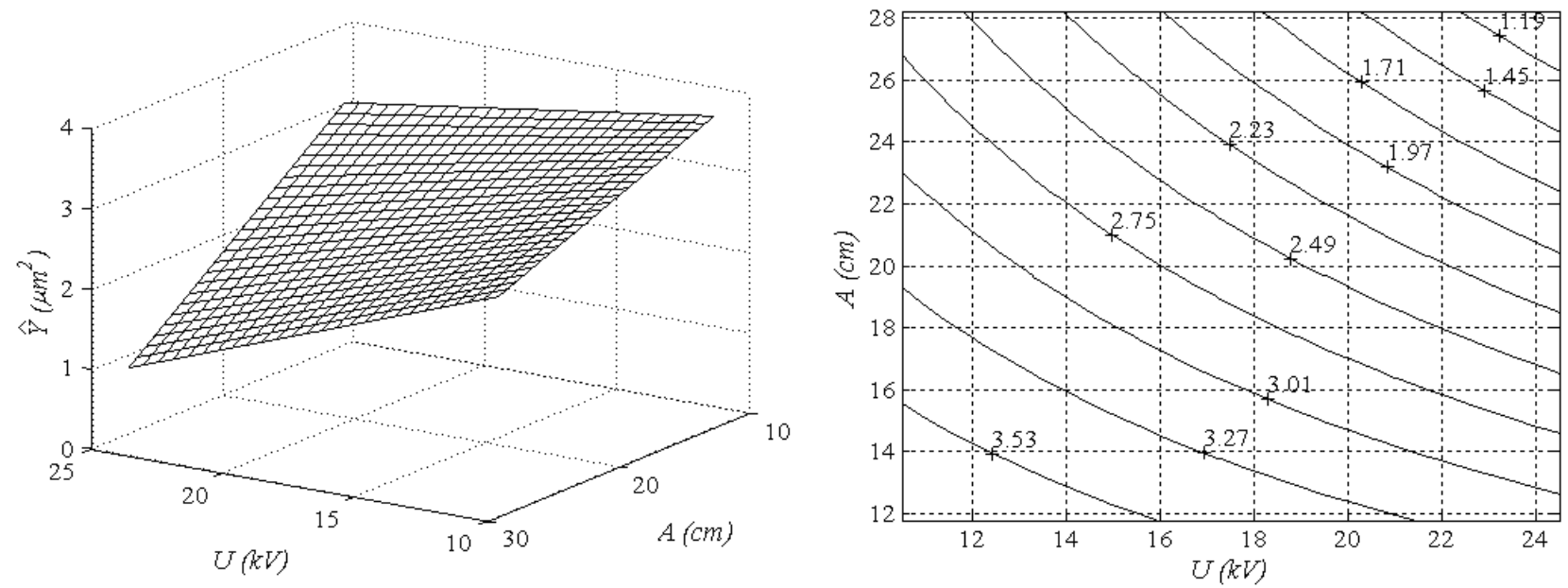

Fig. (5). Quality loss function $(Y)$ versus the variables $U(\mathrm{kV})$ and $A(\mathrm{~cm})$ maintaining $F$ at $2.25 \mathrm{~mL} / \mathrm{h}$.
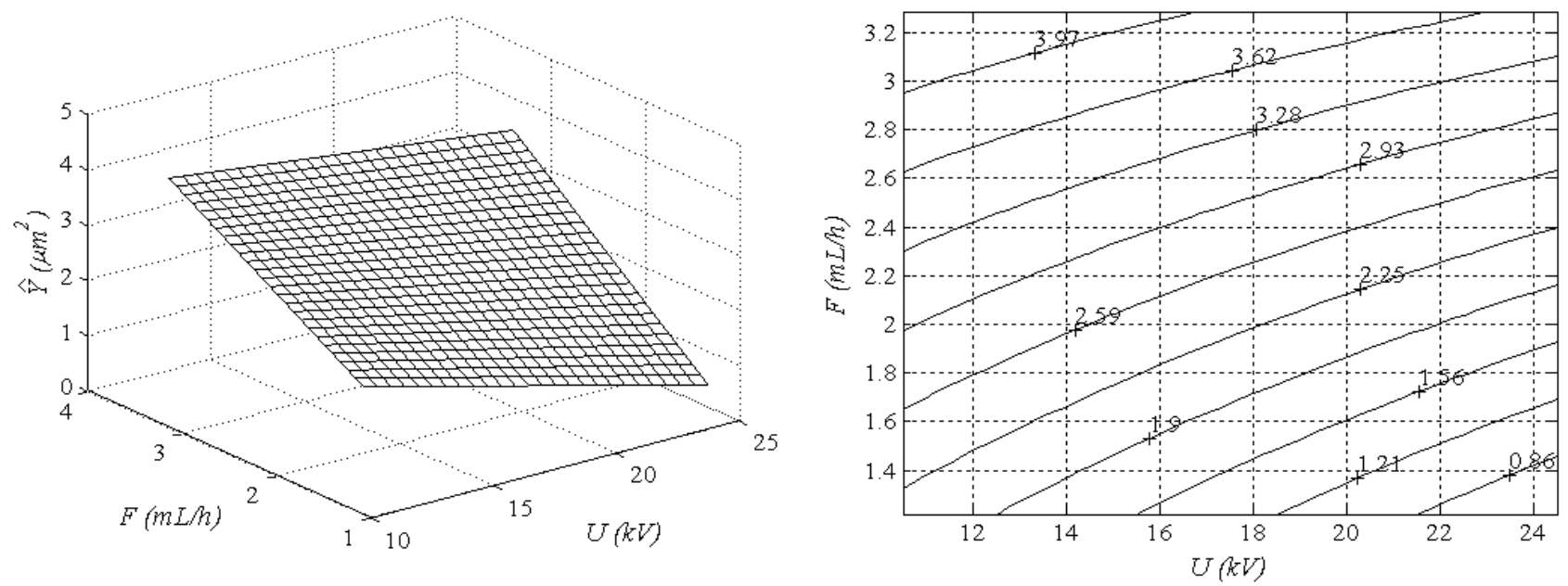

Fig. (6). Quality loss function $(Y)$ versus the variables $U(\mathrm{kV})$ and $F(\mathrm{~mL} / \mathrm{h})$ maintaining $A$ at $20 \mathrm{~cm}$.

This model equation is valid for the following region of experimentation:

$10.5 \leq U \leq 24.5(\mathrm{kV}) ; 11.77 \leq A \leq 28.23(\mathrm{~cm}) ;$

$1.22 \leq F \leq 3.28(\mathrm{~mL} / \mathrm{h})$;
Figs. (4-6) present the response surface plots and contour lines maps of $Y$ as a function of the design variables.

It is known that polymer flow rate determines the quantity of the solution available for electrospinning. When the 
Table 3. Electrospinning Optimal Point Determined by Monte Carlo Method

\begin{tabular}{|c|c|c|c|c|c|c|c|}
\hline \multicolumn{2}{|c|}{ Voltage } & \multicolumn{2}{|c|}{ Collector Distance } & \multicolumn{2}{|c|}{ Polymer Flow Rate } & \multirow[b]{2}{*}{$\begin{array}{c}Y_{\text {predicted }} \\
\left(\mu \mathbf{m}^{2}\right)\end{array}$} & \multirow[b]{2}{*}{$\begin{array}{c}Y_{\text {experimental }} \\
\left(\mu \mathbf{m}^{2}\right)\end{array}$} \\
\hline$x_{1}$ & $U(\mathrm{kV})$ & $x_{2}$ & $A(\mathrm{~cm})$ & $x_{3}$ & $F(\mathbf{m L} / \mathbf{h})$ & & \\
\hline 0.952 & 24.1 & 0.937 & 27.7 & -0.989 & 1.23 & 0.328 & $0.314 \pm 0.099$ \\
\hline
\end{tabular}

polymer flow rate is increased, the diameter of the electrospun fiber is also increased $[18,21]$. If the polymer flow rate is too high, greater volume of polymer solution will be drawn from the needle tip and the electrospinning jet will take more time to dry. As a result, the solvents in the deposited fibers over the collector may not have enough time to evaporate. Therefore, the residual solvent may cause the fibers to fuse together forming denser fibrous membrane. This will affect the volume charge density and the electrical current of the polymer solution, which increase or decrease depending on the polymer solution. Nasir et al. [18] observed that the PVDF fiber diameter decreased with increasing polymer flow rate up to $5 \mu \mathrm{L} / \mathrm{min}$ and then remained constant for higher flow rates.

The flight time of the electrospinning jet along the gap distance may affect considerably the fiber's characteristics. Decreasing the gas distance has the same effect as increasing the electrical voltage inducing higher electric field strength. When the gap distance is too short, the instability of the jet increases and the spinning solution cannot be fully stretched, resulting in greater fiber diameter. When the gap distance is too large, the strength of the electric field becomes weak resulting in an increase of fiber diameter and sometimes electrospinning is hard to accomplish. Depending on the polymer solution parameters, varying the distance may or may not have a significant effect on the fiber morphology. Nasir et al. [18] reported that the gap distance had no significant effect on the PVDF fiber diameter and explained that the increase of the gap distance induced a decrease of the electrical field strength when a constant electrical voltage was applied, whereas the solvent evaporation time of the polymer jet increased. Megelski et al. [21] also observed no significant change of the electrospun polystyrene fiber size with the change of the gap distance. However, inhomogeneous distribution of elongated beads took place when the gap distance was reduced. Park et al. [41] observed a decrease of the diameter of electrospun polyvinylacetate (PVAc) fiber with increasing the gap distance down to a minimum value followed by a gradual increase of the fiber diameter. This is due to the decrease in the electrostatic field strength resulting in less stretching of the fibers and indicates that there is an optimal electrostatic field strength below which the stretching of the solution will decrease resulting in increased fiber diameter. Therefore, the study of interaction effect in electrospinning is of great interest.

Fig. (4) shows the influence of the polymer flow rate $F$ $(\mathrm{mL} / \mathrm{h})$ and the collector distance $A(\mathrm{~cm})$ on $Y$. As can be observed a strong interaction effect exists between these two parameters $F$ and $A$. The decrease of the flow rate reduces $Y$, and due to the mutual interaction between $F$ and $A$ the overall effect of $F$ is more apparent at lower level of $A$. On the contrary, the decrease of the collector distance leads to an enhancement of the quality loss function. Owing to the inter- action effect, the influence of $A$ is tiny at lower $F$ and very strong at higher values of $F$. A high collector distance and low flow rate minimize the quality loss function and improve the performance of the electrospinning process. This can be attributed to the fact that such setting of factors ensures a sufficient time for solvent evaporation.

It is worth quoting that the high voltage will produce the necessary charges on the polymer solution initiating electrospinning process when the electrostatic force in the solution overcomes the surface tension of the solution. When the applied voltage is higher, the greater amount of the induced charges will cause faster acceleration of the electrospinning jet and then a higher quantity of polymer solution will be drawn from the needle tip. These will result in a larger fiber diameter. Depending on the polymer flow rate of the dope and the polymer concentration, a high voltage may be required so that the Taylor cone is stable. The columbic repulsive force in the jet will then stretch the viscoelastic solution. In various cases, a higher electric voltage causes greater stretching of the polymer solution reducing in this way the diameter of electrospun fibers.

Fig. (5) illustrates the effects of $U$ and the collector distance on $Y$. As can be seen, the increment of both variables diminishes the response and improves the electrospinning process performance. The effect of $U$ is stronger at higher levels of $A$, and the effect of $A$ is more evident at high values of $U$. Therefore, according to the predictions, the best result must be obtained for high values of both the applied voltage and the collector distance.

The effects of $U$ and $F$ on $Y$ are plotted in Fig. (6). The graphical analysis reveals that increasing $U$ and decreasing $F$ reduce $Y$. The interaction effects between the applied voltage and the polymer flow rate is minor compared to the previous ones (Figs. 4 and 5). However, the influence of $U$ is stronger at lower levels of $F$. In contrast, the overall effect of $F$ is stronger for higher levels of $U$. According to the response surface plot shown in Fig. (6) the smallest fiber diameters are obtained applying high values of the $U$ and low values of $F$.

To determine the optimum electrospinning conditions, the factorial model (Eq. 4) has been used. Monte Carlo method was employed for stochastic simulations and optimization in order to minimize the objective function. Table $\mathbf{3}$ reports the obtained optimal solution in terms of both coded and actual variables. Experimental confirmation run was performed using the optimum electrospinning conditions in order to confirm or disapprove the optimal point from experimental standpoint. SEM image and histogram of the electrospun PVDF fiber prepared applying the determined optimum experimental conditions are shown in Fig. (7). It was found $4.3 \%$ deviation between the predicted quality loss function and the experimental one confirming the optimal point. 

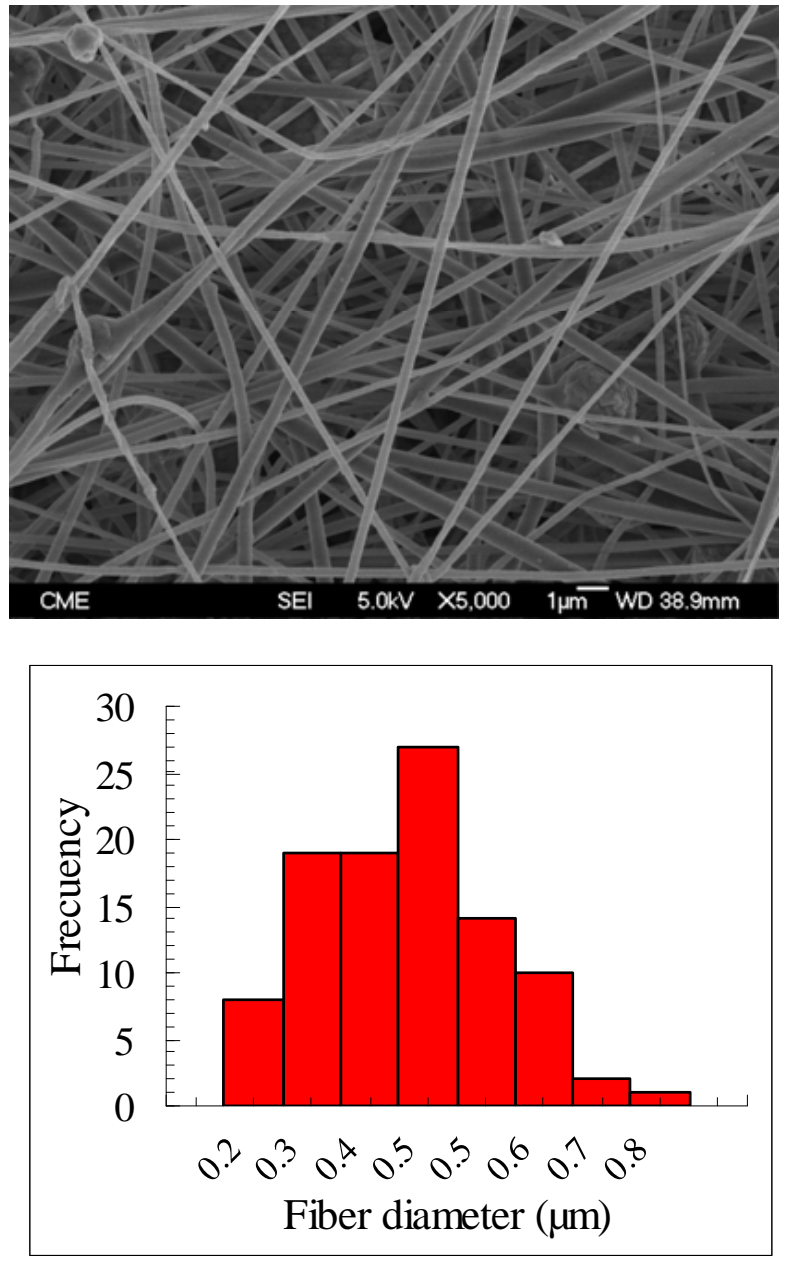

Fig. (7). SEM image and fiber diameter distribution of the electrospun PVDF fiber prepared applying the optimum experimental conditions.

By applying the obtained optimum electrospinning conditions, a PVDF electrospun membrane was prepared during $3 \mathrm{~h} 30 \mathrm{~min}$ electrospinning time and characterized by different techniques as indicated previously. The results are summarized in Table 4. The water contact angle of the prepared optimum PVDF nanofibrous membrane is greater than that of the PVDF nanofibrous membranes reported by Feng et al. [34] and Prince et al. [35] $\left(128^{\circ}\right)$. The obtained high water contact angle in this study is attributed to the distinct PVDF polymer used and to the small fiber diameter achieved of the PVDF electrospun membrane fabricated by optimum electrospinning conditions. Feng et al. [34] and Prince et al. [35] reported a higher $L E P$ values for PVDF electrospun membranes than the $L E P$ values obtained in this study, $121.4 \mathrm{kPa}$ and $90 \mathrm{kPa}$, respectively. These results are due to the distinct PVDF polymer solution used, to the different electrospinning parameters applied and to the different maximum inter-fiber space. For instance, the optimum PVDF electrospun membrane prepared in this study exhibits a higher inter-fiber space $\left(d_{i}\right)$ than those of the PVDF nanofibrous membranes prepared by Feng et al. [34] $(0.32 \mu \mathrm{m})$ and Prince et al. [35] $(0.58-0.64 \mu \mathrm{m})$. Moreover, the void volume fraction $(\varepsilon)$ of the optimum PVDF electrospun membrane is found to be slightly higher than that of the PVDF electrospun membranes prepared by Feng et al. [34] (76\%) and Prince et al. [35] (81\%).

As stated previously, the prepared PVDF membrane was applied for desalination by direct contact membrane distillation (DCMD) using different feed salt $(\mathrm{NaCl})$ concentrations (distilled water, $12 \mathrm{~g} / \mathrm{L}, 30 \mathrm{~g} / \mathrm{L}$ and $60 \mathrm{~g} / \mathrm{L}$ ), $80^{\circ} \mathrm{C}$ feed temperature and $20^{\circ} \mathrm{C}$ permeate temperature. The obtained permeate fluxes were $58.8 \pm 0.2 \mathrm{~kg} / \mathrm{m}^{2} . \mathrm{h}, 57.3 \pm 0.4 \mathrm{~kg} / \mathrm{m}^{2} . \mathrm{h}$, $53.5 \pm 0.4 \mathrm{~kg} / \mathrm{m}^{2}$.h and $51.3 \pm 0.3 \mathrm{~kg} / \mathrm{m}^{2} . \mathrm{h}$, for distilled water, $12 \mathrm{~g} / \mathrm{L}, 30 \mathrm{~g} / \mathrm{L}$ and $60 \mathrm{~g} / \mathrm{L}$, respectively. The salt rejection factors were greater than $99.94 \%$. The observed decrease of the permeate flux with the increase of the feed salt concentration is due to the reduction of the water vapour pressure at the feed/membrane interface, which decrease the driving force (i.e. transmembrane water vapour pressure), and to the concentration polarization effect [32]. Although the thickness of the optimum electrospun membrane prepared in this study is higher than that of the PVDF nanofibrous membranes prepared by Feng et al. [34] and Prince et al. [35], the obtained permeate fluxes are more than 4.4 times greater. The highest permeate flux obtained by Feng et al. [34] for a PVDF electrospun membrane was $11.5 \mathrm{~kg} / \mathrm{m}^{2} . \mathrm{h}$ whereas that reported by Prince et al. [35] was even lower $5.8 \mathrm{~kg} / \mathrm{m}^{2} . \mathrm{h}$. The obtained high permeation flux in the present study may be attributed to the higher size of the inter-fiber space and to the smaller fiber diameter affecting to some extent the mechanism of mass transport through the inter-fiber space of the electrospun nanofibrous membranes [32,33].

\section{CONCLUSIONS}

In this work a full factorial design $2^{3}$ was employed for fabrication of electro-spun PVDF fibers. Three independent variables were considered for the first time in experimental design related to electro-spinning. These variables are the applied voltage, the polymer solution flow rate and the distance between the needle tip and the collector. As response of interest the quality loss function was used. This takes into account both the weighted arithmetic mean of fibers diameter and its dispersion. The main and interaction effects of the electro-spinning variables on experimental response were

Table 4. Characteristics of the PVDF Nanofibrous Membrane Prepared Applying the Optimum Electrospinning Conditions: Void Volume Fraction $(\varepsilon)$, Advancing Water Contact Angle $\left(\theta_{a}\right)$, Mean Size of the Inter-Fiber Space $\left(d_{i}\right)$, Liquid Entry Pressure $(L E P)$ of Distilled Water and NaCl Aqueous Solutions (12 g/L, $30 \mathrm{~g} / \mathrm{L}$ and $60 \mathrm{~g} / \mathrm{L})$

\begin{tabular}{|c|c|c|c|c|c|c|c|}
\hline \multirow{2}{*}{$\varepsilon(\%)$} & \multirow{2}{*}{$\theta_{a}\left({ }^{\circ}\right)$} & \multirow{2}{*}{$\delta(\mu \mathrm{m})$} & \multirow{2}{*}{$d_{i}(\mu \mathrm{m})$} & \multicolumn{4}{|c|}{$L E P(\mathrm{kPa})$} \\
\hline & & & & Distilled Water & $12 \mathrm{~g} / \mathrm{L}$ & $30 \mathrm{~g} / \mathrm{L}$ & $60 \mathrm{~g} / \mathrm{L}$ \\
\hline 81.6 & 150.1 & 567.2 & 0.82 & 33.5 & 37.0 & 40.5 & 42.5 \\
\hline
\end{tabular}


revealed. Thus, a strong interaction effect was detected between polymer flow rate and the collector distance by means of three dimensional surface plot and contour-line map. A high collector distance and a low flow rate both minimize the quality loss function and improve the performance of the electro-spinning process because both ensure a sufficient time for solvent evaporation through the air gap of the polymer jet. Finally, the optimal point was determined using the factorial model and Monte Carlo optimization method. Under the obtained optimum operating conditions, $1.23 \mathrm{~mL} / \mathrm{h}$ polymer flow rate, $24.1 \mathrm{kV}$ voltage and $27.7 \mathrm{~cm}$ air gap a small PVDF nano-fiber diameter and narrow dispersion were obtained experimentally.

The fabricated membrane applying the determined optimum electrospinning parameters was characterized by different techniques and applied for desalination by direct contact membrane distillation (DCMD). The obtained permeate fluxes were $58.8 \pm 0.2 \mathrm{~kg} / \mathrm{m}^{2} . \mathrm{h}, 57.3 \pm 0.4 \mathrm{~kg} / \mathrm{m}^{2} . \mathrm{h}, 53.5 \pm 0.4$ $\mathrm{kg} / \mathrm{m}^{2} . \mathrm{h}$ and $51.3 \pm 0.3 \mathrm{~kg} / \mathrm{m}^{2} . \mathrm{h}$, for distilled water, $12 \mathrm{~g} / \mathrm{L}, 30$ $\mathrm{g} / \mathrm{L}$ and $60 \mathrm{~g} / \mathrm{L}$ salt $(\mathrm{NaCl})$ aqueous solutions, respectively; with salt rejection factors greater than $99.94 \%$. These permeate fluxes are more than 4.4 times greater than those reported so far for electrospun nanofibrous membranes used in membrane distillation (MD).

The statistical experimental design and response surface methodology can be applied for other polymer solutions and other electrospinning environmental conditions (Temperature and humidity). Different regression coefficients (Eq. 4) and different optimum electrospinning conditions may be obtained.

\section{CONFLICT OF INTEREST}

The authors confirm that this article content has no conflicts of interest.

\section{ACKNOWLEDGEMENTS}

The authors gratefully acknowledge the financial support of the I+D+I project MAT2010-19249 (Spanish Ministry of Science and Innovation). M. Essalhi is thankful to the Middle East Desalination Research Centre (MEDRC, Project 06AS-02).

\section{REFERENCES}

[1] Li, D.; Xia, Y. Electrospinning of nanofibers: reinventing the wheel. Adv. Mater., 2004, 16, 1151.

[2] Ramakrishna, S.; Fujihara, K.; Teo, W.E.; Yong, T.; Ma, Z.; Ramaseshan, R. Electrospun nanofibers: solving global issues. $\mathrm{Ma}$ ter. Today, 2006, 9, 40.

[3] Bhardwaj, N.; Kundu, S.C. Electrospinning: A fascinating fiber fabrication technique. Biotechnol. Adv., 2010, 28, 325.

[4] Huang, Z.M.; Zhang, Y.Z.; Kotaki, M.; Ramakrishna, S. A review on polymer nanofibers by electrospinning and their applications in nanocomposites. Compos. Sci. Technol., 2003, 63, 2223.

[5] Liang, D.; Hsiao, B.S.; Chu, B. Functional electrospun nanofibrous scaffolds for biomedical applications. Adv. Drug Deliv. Rev., 2007, 59, 1392.

[6] Jang, J.H.; Castano, O.; Kim, H.W. Electrospun materials as potential platforms for bone tissue engineering. Adv. Drug Deliv. Rev., 2009, 61, 1065 .

[7] Baji, A.; Mai, Y.W.; Wong, S.C.; Abtahi, M.; Chen, P.Electrospinning of polymer nanofibers: Effects on oriented morphology, structures and tensile properties. Compos. Sci. Technol., 2010, 70, 703 .
[8] Casper, C.; Stephens, J.; Tassi, N.; Chase, D.; Rabolt, J. Controlling surface morphology of electrospun polystyrene fibers: effect of humidity and molecular weight in the electrospinning process. Macromolecules, 2004, 37, 573.

[9] Zhang, D.; Chang, J. Electrospinning of three-dimensional nanofibrous tubes with controllable architectures. Nano Lett., 2008, 8, 3283.

[10] Jiang, H.L.; Fang, D.F.; Hsiao, B.S.; Chu, B.; Chen, W.L. Optimization and characterization of dextran membranes prepared by electrospinning. Biomacromolecules, 2004, 5, 326.

[11] Yee, W.A.; Kotaki, M.; Liu, Y.; Lu, X. Morphology, polymorphism behavior and molecular orientation of electrospun poly(vinylidene fluoride) fibers. Polymer, 2007, 48, 512.

[12] Rietveld, I.B.; Kobayashi, K.; Yamada, H.; Matsushige, K. Morphology control of poly(vinylidene fluoride) thin film made with electrospray. J. Colloid Interface Sci., 2006, 298, 639.

[13] Choi, S.W.; Jo, S.M.; Lee, W.S.; Kim, Y.R. An electrospun poly (vinylidene fluoride) nanofibrous membrane and its battery applications. Adv. Mater. 2003, 15, 2027.

[14] Zhao, Z.Z.; Li, J.Q.; Yuan, X.Y.; Li, X.; Zhang, Y.Y.; Sheng, J. Preparation and properties of electrospun poly (vinylidene fluoride) membranes. J. Appl. Polym. Sci., 2005, 97, 466.

[15] Haghi, A.K.; Akbari, M. Trends in electrospinning of natural nanofibers. Phys. Status Solidi 2007, 204, 1830.

[16] Deitzel, J.M.; Kleinmeyer, J.; Harris, D.; Tan, N.C.B. The effect of processing variables on the morphology of electrospun nanofibers and textiles. Polymer, 2001, 42, 261.

[17] Ki, C.S. ;Baek, D.H.; Gang, K.D.; Lee, K.H.; Um, I.C.; Park, Y.H. Characterization of gelatin nanofiber prepared from gelatin-formic acid solution. Polymer, 2005, 46, 5094.

[18] Nasir, M.; Matsumoto, H.; Danno, T.; Minagawa, M.; Irisawa, T.; Shioya, M.; Tanioka, A. Control of diameter, morphology, and structure of PVDF nanofiber fabricated by electrospray deposition. J. Polym. Sci. Part B: Polym. Phys., 2006, 44, 779.

[19] Reneker, D.H.; Yarin, A.L. Electrospinning jets and polymer nanofibers. Polymer 2008, 49, 2387.

[20] Yördem, O.S.; Papila, M.; Menceloğlu, Y.Z. Effects of electrospinning parameters on polyacrylonitrile nanofiber diameter: an investigation by response surface methodology. Mater. Design, 2008, 29, 34.

[21] Megelski, S.; Stephens, J.S.; Chase, D.B.; Rabolt, J.F. Micro-and nanostructured surface morphology on electrospun polymer fibers. Macromolecules, 2002, 35, 8456.

[22] Donglai, W.; Zhenshan, C.; Jun, C. Optimization and tolerance prediction of sheet metal forming process using response surface model. Computational Mater. Sci., 2008, 42, 228.

[23] Khayet, M. ;Cojocaru, C.; Zakrzewska-Trznadel, G. Response surface modelling and optimization in pervaporation. J. Membr. Sci., 2008, 321, 272.

[24] Idris, A.; Kormin, F.; Noordin, M.Y. Application of response surface methodology in describing the performance of thin film composite membrane. Sep. Purif. Technol., 2006, 49, 271.

[25] Khayet, M.; Cojocaru, C.; García-Payo, M.C. Application of response surface methodology and experimental design in direct contact membrane distillation. Ind. Eng. Chem. Res., 2007, 46, 5673.

[26] Ismail, A.F.; Lai, P.Y. Development of defect-free asymmetric polysulfone membranes for gas separation using response surface methodology. Sep. Purif. Technol., 2004, 40, 191.

[27] Khayet, M.; Cojocaru, C.; García-Payo, M.C. Experimental design and optimization of asymmetric flat-sheet membranes prepared for direct contact membrane distillation. J. Membr. Sci., 2010, 351, 234.

[28] Khayet, M.; Abu Seman, M.N.; Hilal, N. Response surface modeling and optimization of composite nanofiltration modified membranes. J. Membr. Sci., 2010, 349, 113.

[29] Cui, W.; Li, X.; Zhou, S.; Weng, J. Investigation on process parameters of electrospinning system through orthogonal experimental design. J. Appl. Polym. Sci., 2007, 103, 3105.

[30] Gu, S.Y.; Ren, J.; Vansco, G.J. Process optimization and empirical modeling for electrospun polyecrylonitrile (PAN) nanofiber precursor of carbon nano-fibers. Eur. Polym. J., 2005, 41, 2559.

[31] Khayet, M.; García-Payo, M.C. Nanostructured flat membranes for direct contact membrane distillation, PCT/ES2011/000091, WO/2011/117443, 2011.

[32] Khayet, M.; Matsuura T. Membrane distillation: Principles and applications, Elsevier: The Netherlands, 2011. 
[33] Khayet, M. Membranes and theoretical modeling of membrane distillation: a review. Adv. Colloid Interface Sci., 2011, 164(1-2), 56.

[34] Feng, C.; Khulbe, K.C.; Matsuura, T.; Gopal, R.; Kaur, S.; Ramakrishna, S.; Khayet, M. Production of drinking water from saline water by air-gap membrane distillation using polyvinylidene fluoride nanofiber membrane. J. Membr. Sci., 2008, 311, 1.

[35] Prince, J.A.; Singh, G.; Rana, D.; Matsuura, T.; Anbharasi, V.; Shanmugasundaram, T.S. Preparation and characterization of highly hydrophobic poly(vinylidene fluoride)-clay nanocomposite nanofiber membranes (PVDF-clay NNMs) for desalination using direct contact membrane distillation. J. Membr. Sci., 2012, $397-$ 398,80

[36] Essalhi, M.; Khayet, M. Surface segregation of fluorinated modifying macromolecule for hydrophobic/hydrophilic membrane prepa- ration and application in air gap and direct contact membrane distillation. J. Membr. Sci., 2012, 417-418, 163.

[37] Taloi, D.; Bratu, C.; Florian, E.; Berceanu, E. Optimization of the metallurgical processes, (in Romanian), Didactica \& Pedagogica Publisher: Bucharest, 1983.

[38] Alexis, J. Taguchi method applied for industrial practice: Experimental designs, (in Romanian), Tehnica Publisher: Bucharest, 1999.

[39] Akhnazarova, S.; Kafarov, V. Experiment optimization in chemistry and chemical engineering, Mir Publisher: Moscow, 1982.

[40] Montgomery, D.C. Design and Analysis of Experiments, 5th ed.; Wiley \& Sons: New York, 2001

[41] Park, J.Y.; Lee, I.H.; Bea, G.N. Optimization of the electrospinning conditions for preparation of nanofibers from polyvinylacetate (PVAc) in ethanol solvent. J. Ind. Eng. Chem., 2008, 14, 707.

(C) Essalhi et al.; Licensee Bentham Open.

This is an open access article licensed under the terms of the Creative Commons Attribution Non-Commercial License (http://creativecommons.org/licenses/by-nc/3.0/) which permits unrestricted, non-commercial use, distribution and reproduction in any medium, provided the work is properly cited. 